\title{
DESIGNING A NO-FAULT ALTERNATIVE
}

\author{
LAURENCE R. TANCREDI*
}

\section{INTRODUCTION}

A no-fault compensation scheme should rank at the very top of a list of long-term solutions to the perceived crisis in medical malpractice. The form of no-fault system most likely to be adopted would be one providing automatic compensation, not for all iatrogenic injuries, but for a limited set of "designated compensable events." Such a compensation system would be closely integrated with the day-to-day activities of health care providersindividual practitioners, institutions, and health maintenance organizations (HMO's) - and would link compensation closely to the outcomes of medical intervention. In addition to providing quick and equitable compensation for a wide range of medically caused injuries, a properly designed system would supply strong incentives for modifying provider behavior to improve the quality of health care. ${ }^{1}$

Although a no-fault scheme might be embodied in legislation, this idea has not yet been embraced by public policy makers. Nevertheless, it remains possible (subject to concerns about the enforceability of agreements modifying tort rights) for a no-fault scheme to be adopted privately in provider/patient contracts backed by a form of casualty insurance. In the current competitive environment of the health care industry, the availability of the voluntary no-fault alternative would greatly expand the freedom of choice of both providers and consumers of health care services. ${ }^{2}$

II

\section{Prospects of a No-Fault System}

The long-term prospects for a no-fault alternative to the existing tort system of medical injury compensation look optimistic for several reasons. A no-fault compensation mechanism would be far more effective than the much maligned fault system in achieving the twin goals that the tort system is supposed to serve-fair compensation and deterrence. To begin with, a no-

\footnotetext{
Copyright $@ 1986$ by Law and Contemporary Problems

* Professor of Medicine and the Law and Director, Health Law Program, University of Texas Health Science Center, Houston, Texas.

1. Havighurst, "Medical Adversity Insurance"-Has Its Time Come?, 1975 DUkE L.J. 1233, 124 1-49; Havighurst \& Tancredi, "Medical Adversity Insurance" - A No-Fault Approach to Medical Malpractice and Qualily Assurance, 51 HeALTH \& SOC'Y 125, 128-30, 160 (1973).

2. See Havighurst, Reforming Malpractice Through Consumer Choice, Health Aff., Winter 1984, at 63, 65-66.
} 
fault system would effectively and fairly compensate those whose injuries fall within its scope. The tort system is arguably inequitable in that its decisionmaking processes do not always yield consistent results on similar facts. ${ }^{3}$ In addition, whether similar injuries will or will not be compensated depends upon the fortuitous factor of the victim's ability to prove provider fault. Although a no-fault scheme would almost certainly not undertake to compensate all patients whose encounters with the health care system produced a regrettable result, its coverage would be more extensive and more systematic than that of the present system.

A no-fault system would also be more successful than the tort system in preventing injuries through deterrence. ${ }^{4}$ Evidence showing iatrogenic illness to be frighteningly common and frequently serious ${ }^{5}$-especially in the hospital context ${ }^{6}$-indicates that the tort system in its present form leaves many avoidable injuries uncompensated. ${ }^{7}$ Without fairly systematic compensation, it is likely that injuries are suboptimally deterred, confirming the fears of many that the tort system fails to deter even those injuries that would be compensable under its own restrictive rules. ${ }^{8}$ Moreover, because liability insurance, priced largely on the basis of community rather than individual experience, insulates each physician against the true financial cost of his detected negligence, the impression is reinforced that the existing tort system creates inadequate incentives for accident avoidance. In contrast to the tort system's primary reliance on stigma and publicity to induce better provider performance, a properly designed no-fault approach would contain appropriate financial incentives-through experience rating of providers-for the prevention of injuries. It would also generate systematic data about adverse events in a form permitting statistical analysis and comparison with results at other treatment centers. This information could be fed back to the responsible practitioners, who could modify their behavior to decrease the accident rate in their facility.

3. Williams, Abandoning Medical Malpractice, 5 J. Legal MED. 549, 577-80 (1984).

4. Aba Comm'n on Medical Prof. liab., Designated Compensable Event System: A Feasibility Study 2 (1979); see Havighurst \& Tancredi, supra note 1, at 139.

5. Cal. Medical Ass'n and Cal. Hosp. Ass'n, Report on the Medical Insurance Feasibility STudY (D. Mills ed. 1977); Williams, supra note 3, at 570-77.

6. Furrow, Iatrogenesis and Medical Error: The Case for Medical Malpractice Litigation, 9 LAw MED. \& Health Care 4, 4 (1981); Steel, Gertman, Crescenzi \& Anderson, Iatrogenic Illness on a General Medical Service at a University Hospital, 304 NEw ENG. J. MEd. 638, 639 (1981).

7. Pocincki, Dogger \& Schwartz, The Incidence of Iatrogenic Injuries, in U.S. DEP'T of HEALTH, Education, and Welfare, Report of the Secretary's Commission on Medical Malpractice \& APPENDIX 19.20 (1973).

8. Furthermore, the results of such illness can be critical. One researcher disclosed the results of a study that the consequences to 16 patients suffering from avoidable adverse outcomes following colonic surgery were very serious: this population had ten times the mortality, seven times the average cost, and four times the length of hospitalization as those undergoing the colonic surgery who suffered no complication. Couch, Tilney \& Moore, The Cost of Misadventures in Colonic Surgery, 135 AM. J. Surgery 641, 646 (1978). The same authors concluded in another surgical study that "medical misadventure blends into the dense matrix of high-technology medicine and is easily obscured by it." Couch, Tilney, Rayner \& Moore, The High Cost of Low-Frequency Events, 304 NEw ENG. J. MED. 634, 637 (1981). 
Another attraction of a no-fault system is that it could function more efficiently than the current tort system. ${ }^{9}$ Although estimates vary considerably on the extent to which liability insurance premiums are consumed by administrative expenses and never reach injured patients, the tort system's transaction costs are very high, certainly well over fifty cents on each dollar. ${ }^{10}$ By eliminating the need to evaluate fault in every case and to litigate the issue exhaustively in many of them, a no-fault system would save resources that could be better applied to compensating patients.

In addition to having the foregoing advantages over the existing tort system, the no-fault approach would bring about a minimization of undesirable medical practices falling under the label of "defensive medicine." Estimates of the cost of defensive medicine are at best speculative, and there have been no good studies to delineate the precise range and impact of defensive practices." On the other hand, various groups have offered their opinions. In a recent report, the American Medical Association suggested that the defensive practice of medicine is widespread, amounting to over $\$ 15$ billion annually. ${ }^{12}$ It would be wrong to suggest that all activities inspired by the tort system and designated as defensive practices are undesirable; some such activities enhance the quality of health care outcomes and should be encouraged. ${ }^{13}$ But to the extent that costs are incurred without benefit to the patient or patients are exposed to unnecessary and risky diagnostic procedures, defensive practices create additional burdens on the public. By avoiding public accusations of malpractice and the stigma attached to them, a no-fault system would neutralize the motivational factors responsible for defensive medical practices that provide no net benefit to patients.

The changing patterns of medical practice also point up the logic of moving in the direction of a no-fault system. The development of HMO's and large hospital conglomerates and the increasing involvement of employers in controlling the cost of their employees' health care have brought about profound changes in the structure of health care delivery. ${ }^{14}$ The old system of physician-dominated health care provided little choice for the consumer. The diversity resulting from HMO's and competitive medical plans of other kinds is inevitably offering consumers new options and opportunities to economize on the amount and quality of health care obtained and to seek the best financial protection and quality of care attainable at reasonable cost. In this new climate, concern about the costs generated by the malpractice situation

9. See J. O'Connell, Ending Insult to Injury: No-Fault Insurance for Products and Services 97-111 (1975); Havighurst \& Tancredi, supra note 1, at 142-43.

10. Institute of Medicine, National Academy of Sciences, Beyond Malpractice: Compensation for Medical Injuries 13 (1978); Shapiro, Medical Malpractice: History, Diagnosis and Prognosis, 22 ST. Louis U.L.J. 469, 471 (1978).

11. Tancredi \& Barondess, The Problem of Defensive Medicine, 200 Science 879, 879 (1978).

12. AMA Study Reports Sharp Increase in Malpractice Claims Against Physicians, Med. Liab. Advis. SERVICE, Jan. 1980, at 16. 49.

13. Project, The Medical Malpractice Threat: A Study of Defensive Medicine, 1971 Duke L.J. 939, 948-

14. Havighurst, supra note 2, at 65-66. 
and about the alignment of the compensation system with quality-of-care objectives should make no-fault alternatives increasingly attractive. ${ }^{15}$

Other factors that increase the likelihood that a no-fault system will receive increasing attention in the future include the widespread dissatisfaction with the existing tort system and the recurrent sense of crisis that surrounds it. Although primary emphasis is currently being placed on legislative tinkering with the existing system, logic points toward increasing private innovation as well. What is at stake is nothing less than the definition of the physician/patient relationship. The overriding issue is whether the terms of that intensely personal relationship ought to be prescribed exclusively by government through political and legal processes or whether the relationship should instead be shaped at least in part through private negotiation of mutually satisfying arrangements. No-fault insurance offers an attractive opportunity to strengthen physician/patient bonds and to shore up the values of honesty and trust that are essential to a healthy, happy, and therapeutic relationship. ${ }^{16}$ Clinicians and others have observed that the current adversary system, which threatens to pit a patient against a health care professional in an acrimonious dispute, discourages the physician from revealing to the patient his doubts and the full truth about the outcomes of his management because such disclosures may trigger a malpractice suit. ${ }^{17}$ A no-fault scheme, by which a provider acknowledges risks and undertakes to protect patients against specific harms, should strengthen and improve both the subjective and the objective quality of care.

\section{III}

\section{Specifications for a No-Fault Plan}

An ideal no-fault program would guarantee adequate compensation for all medically induced injuries. Upon the occurrence of these events, a patient would automatically receive compensation for economic losses (medical care expenses and loss of wages) without the necessity of proving negligence through a tort claim. In order to maintain provider responsibility for adverse outcomes, the payment would come from a provider-purchased insurance policy under which premiums and other features preserve provider incentives to prevent or minimize the cost of injuries.

The most obvious problem with this ideal no-fault system is the high cost of making health care providers insurers of good medical results for all their patients. Moreover, such extensive coverage is not indicated on policy or any other grounds. For one thing, it would duplicate financial protection that most patients already have against medical expenses, death, and disability. In addition, there would be great difficulty in distinguishing harms brought about by treatment-iatrogenic injuries-from the natural consequences of

15. Tancredi, Designated Compensable Events: A No-Fault Approach to Medical Malpractice, 10 LAW Med. \& Health Care 200, 200-03 (1982).

16. R. Veatch, A Theory of Medical Ethics 8, 214-16 (1981).

17. Williams, supra note 3 , at 577 . 
the patient's underlying disease or condition. Moreover, many of the compensated harms would be unavoidable side effects of therapy the net effect of which was decidedly beneficial, perhaps the best that could be expected. For these and other reasons, a practical no-fault scheme would be confined to covering a limited set of adverse outcomes that were specified in advance-“designated compensable events" (DCE's). Patients suffering adverse outcomes not appearing on the predefined list would remain free to bring tort actions under traditional principles. Obviously, the extent to which the problems of the existing tort system would be obviated by substituting nofault compensation would depend upon the scope of the DCE list.

The criteria for listing adverse medical outcomes as DCE's are crucial. Presumably, the list should be developed by medical experts who are concerned about protecting consumer interests and creating desirable quality-of-care incentives as well as about letting providers avoid tort actions (and large recoveries) for obvious negligence. The major criterion for the identification of DCE's should be the relative avoidability of the outcome under good medical practice. ${ }^{18}$ The idea would not be to list only outcomes that were always avoidable or that could occur only under negligent management; instead, if the statistical incidence of an outcome could be reduced by good practice, it would be a candidate for listing even if the risk of harm could not be eliminated altogether. This test would focus not only on the extent to which the outcome is preventable, but also on whether it is treatable once it occurs, so that the economic loss to the patient could be minimized.

An equally important criterion would be the medical detectability of the event. The individual DCE must be so clearly defined that it would be readily identifiable and distinguishable without litigation from noncompensable events. The third criterion in judging DCE's would be the impact that compensating for a particular adverse outcome would have on the overall quality of health care. In addition to the incentive created to prevent the outcome, there is also a risk that physicians would be induced to make inappropriate therapeutic choices, avoiding risks that it would be in the patient's interest to run. Thus, the selection of an adverse outcome as a DCE would require a multifactorial analysis going beyond strict medical notions of causation and relative avoidability.

In 1977, the American Bar Association's Commission on Medical Professional Liability conducted a study to determine the feasibility of a DCE system. This project involved data from studies by the National Association of Insurance Commissioners of tort claims in two specialties, general surgery and orthopedic surgery. Panels of specialists, convened to evaluate the economically prominent adverse events emerging from the data, agreed that several of these untoward outcomes would be appropriate DCE's. Despite the complexities of differentiating those risks associated with the care itself from

18. Havighurst \& Tancredi, supra note 1 , at 135-36. 
those associated with patients' underlying medical conditions, the ABA Commission concluded that this study had demonstrated the feasibility of developing such a listing from the universe of treatment-related injuries. ${ }^{19}$ Although some have questioned the practical feasibility of developing a workable list of DCE's, these intuitive criticisms are far less authoritative than the ABA evaluation. ${ }^{20}$

In addition to making no-fault concepts potentially practical in the health care field, the DCE approach has several other advantages. One is its flexibility. The DCE list can be updated periodically as panels of specialists accept new adverse outcomes as deserving of compensation. The ease with which adverse outcomes can be added to (or removed from) the list is essential in a health care system in which new diagnostic and treatment technologies are constantly being introduced, creating opportunities for a wide range of mishaps. The list can also be expanded or contracted in light of financial considerations and the relative attractiveness or unattractiveness of the tort system. ${ }^{21}$

Predefinition of compensable events also links compensation to quality assurance efforts and prevention. ${ }^{22}$ Providers of health care are on notice concerning adverse outcomes that are likely to occur and are implicitly advised that they are avoidable through careful monitoring of the treatment process. Whereas most quality assurance mechanisms operating in the health care field focus on the quality of inputs employed (personnel licensure is one example) or on the processes employed (evaluation by peer review bodies, for example), the DCE approach focuses the attention primarily on outcomes-the only matter of concern to the patient.

The fact that the DCE system focuses on avoidable outcomes and maintains provider responsibility through experience rating suggests that it is not in fact a major departure from the fault system, and indeed it is not. It is a conceptually sound middle ground between a fault system and one that, like no-fault auto insurance, would exonerate providers from responsibility. ${ }^{23}$ It differs from the fault system, however, in dispensing with a case-by-case determination of negligence and the specific attribution of provider fault. It would seem, in short, to offer the best of both worlds-wider compensation and better deterrence of poor practice.

Aside from the problem of designing a workable DCE list, the implementation problems seem relatively straightforward. Decisions regarding the level and character of compensation would have to be made.

19. ABA Comm'n on Medical Prof. Liab., supra note 4, at 5.

20. See P. Danzon, Medical Malpractice: Theory, Evidence, and Public Policy 217-18 (1985); Calabresi, The Problem of Malpractice - Trying to Round Out the Circle, in THE Economics of Medical Malpractice 233, 239 (S. Rottenberg ed. 1978); Epstein, Medical Malpractice: Its Cause and Cure, in The Economics of Medical Malpractice 245, 260-62 (S. Rottenberg ed. 1978).

21. ABA Comm'n on Medical Prof. Liab., supra note 4, at 2.

22. See generally G. Calabresi, The Costs of Accidents: A legal and Economic Analysis (1970).

23. ABA Comm'n on Medical Prof. Liab., supra note 4, at 2-3. 
For example, should minimum or maximum payments for loss of wages be provided for? Should any allowance be made for pain and suffering? More complex issues might be encountered in trying to align the details of the system with incentives that would appropriately influence provider behavior to promote the quality of care. An especially troublesome issue would be whether to allow patients compensated by collateral sources to enjoy a windfall so that incentives for avoiding DCE's would not be diluted. One suggestion is that collateral sources should be indemnified under the providers' insurance policy. Another feature that has been proposed is an obligation on the part of providers to disclose the occurrence of a DCE, discouraging coverups and ensuring that those who are injured receive compensation.

\section{IV}

\section{Selling the No-Fault Concept}

Although the idea of a no-fault system based on DCE's has been around for some time, it has yet to be embraced as a practical program. Many have been concerned that, by compensating automatically a wide range of injuries, a DCE scheme would cost more than the existing system. ${ }^{24}$ Although there are no real data to support that fear, ${ }^{25}$ it is a real concern. Despite the likelihood of real savings in transaction and administrative costs and in improved outcomes resulting from strengthened quality incentives, a well designed DCE-based no-fault program should indeed compensate many injuries that are not now the object of malpractice claims and might well entail higher dollar outlays than for malpractice insurance. ${ }^{26}$ Although many observers are concerned only about this apparent bottom line, reflection should make it clear that a DCE system would create no new costs but would only transfer costs already being borne by other insurance programs or by injured patients to providers (and ultimately to the consuming public, which is bearing them already in other ways). When one offsets against the aggregate dollar costs the savings in administrative costs, the anticipated improvements in the quality of care, the benefits to other public or private collateral sources (assuming their indemnification), and the reduced hardships of injured patients, it is hard to see how the net social and ultimately private gain would not be substantial.

Because of its radical nature and the lack of solid data concerning its impact, the DCE approach is not likely to be embodied in legislation anytime soon. A more practical approach for the present would be a "halfway"

24. Somers, The Malpractice Controversy and Quality of Patient Care, 55 Health \& Soc'y 193, 224 (1977).

25. But cf. Mills, Medical Insurance Feasibility Study, 128 W.J. Med. 360, 363-65 (1978). Mills states that in California only $17 \%$ of potentially compensable events were likely to result in tort compensation. Thus, the cost of automatically compensating the remaining $83 \%$ of potentially compensable events, or even a more limited number of DCE's, could be considerably higher than the existing system.

26. Havighurst \& Tancredi, supra note 1, at 152-56. 
measure whereby a provider or provider group would agree with consumers to compensate them automatically for injuries appearing on a list of DCE's. The patient in turn would agree to surrender his tort rights with respect to any such injury, thus giving up his small statistical chance for a big award including pain and suffering in return for assured payment of his economic losses in a much wider class of cases. Lawyers will of course wrinkle their brows over such contracts and will hope to earn big fees litigating over their enforceability. Assuming, however, that the agreement is reached under circumstances that do not suggest overreaching and that the DCE list is long enough to be fair to the patient-that is, that it really does increase his protection against uncompensated injury-the agreement should certainly be enforced. It is regrettable that the legal system makes such innovations so uncertain, but the benefits of implementing the DCE approach are great enough that parties should proceed even in the face of cautious legal advice.

Adoption by private contract of a no-fault compensation system based on DCE's would square well with developments occurring in the health care field, particularly the trend toward HMO's. In an HMO, relationships are primarily defined by a contract that obligates the subscriber to pay a predetermined fee and the provider to deliver the care necessary for the subscriber's wellbeing. ${ }^{27}$ In addition to being subject to some regulation, HMO's must bargain with sophisticated employers and employee organizations and will have little opportunity to impose unfair provisions. Although HMO subscriber contracts have usually stated the HMO's obligation in general terms and presumed the applicability of noncontractual tort standards, they could easily include a performance standard that permitted some deviation from customary practice and replaced tort remedies with no-fault compensation using DCE's.

An advantage of introducing the DCE system by voluntary agreement rather than on a systemwide basis is the opportunity to start small and experiment with the concept. For example, an HMO might introduce a DCE system for a limited class of treatments or patients, or a single-specialty group practice-orthopedic surgeons or obstetricians, for example-might offer a no-fault plan to its patients, perhaps on an optional basis. In a pilot program the patient population might be subdivided in various ways to eliminate highrisk patients and to ensure the program's actuarial soundness. As providers and insurers were able to accumulate data on incidence of adverse outcomes and experience in administering no-fault compensation, the system could gradually. expand to cover more and more patient injuries, whether or not they presented appreciable malpractice problems. At the outset, the DCE list would probably be conservative, comprised of only the most avoidable and economically prominent adverse outcomes. Although legally it may be necessary that the list not be too short and cover a significant number of

27. Henderson, Putting the DCE Lists to Work: Alternative Approaches to Establishing a Compensation System for Victims of Medical Accidents, in ABA Comm'N ON Medical Prof. Liab., supra note 4, at 53, 57. 61 . 
outcomes that would not have been readily compensated under the tort system, the early no-fault schemes may be less extensive than they might eventually become. The ultimate benefit of private experimentation with nofault compensation might be legislation substituting a DCE system for the traditional tort recoveries. Such legislation might be compulsory or might leave private parties to decide for themselves whether to participate.

System costs in early no-fault plans would probably be no less than the cost of liability insurance covering the same class of injuries. (Indeed, if the DCE list were to cover only outcomes that are so obviously caused by negligence that they are almost automatically compensable by the tort system, the scheme would risk being struck down by the courts as lacking in a quid pro quo or mutuality-reducing awards to injured persons without significantly expanding the class of persons compensated.) The lack of significant dollar savings ought not to be decisive, however, if in fact the parties can all benefit by eliminating litigation with its high costs-in acrimony and emotional wear and tear as well as in dollars. If providers could see their patients compensated for unfortunate events without regard to whether they were caused by negligence, they would undoubtedly find the same, or even a higher, cost worth paying. By the same token, consumers might decide that higher costs for health care were justified in order to have adverse outcomes covered under a DCE no-fault system. Moreover, if the incentive effects of the DCE system improve the quality of care, costs might actually fall. In any event, patients might find that they were getting better value, justifying somewhat higher prices. Thus, both providers and patients might come to attach a high value to a system in which patient grievances do not become acrimonious lawsuits, compensation softens the burden of poor results, providers are accountable for the quality of outcomes, trust and confidence can be maintained between provider and patient, and there is no need for lawyers to become involved.

\section{Conclusion}

Forces operating in the health care system make no-fault compensation a desirable solution to the dilemma posed by the tort system of compensation for medical injury. In the highly competitive environment that is becoming increasingly pervasive in the health care system, various competitive medical plans are allowing consumers to engage in an equal dialogue with providers regarding the nature of their relationship and their respective rights and obligations. Increasing sensitivity to the ethical aspects of the provider/consumer relationship and to the need for cost-saving measures points to private contractual arrangements for the resolution of a wide variety of health care issues. There are good reasons why compensation for medical injuries should become an item in the bargaining between providers and consumers for the first time and why a no-fault approach should attract increasing interest. 
The tort system of medical injury compensation has failed at two of its most important goals-the equitable compensation of injured patients and the creation of incentives for injury avoidance. A no-fault system based on designated compensable events offers an approach that should correct these deficiencies, allow for maximum flexibility concerning the extent and degree of coverage, and restore to the physician/patient relationship the trust and confidence that are essential if the health care system is to work effectively. It is indeed fortunate that the emergence of effective consumer choice allows for creative experimentation with innovative alternatives to the existing medical malpractice system. 